\title{
Calorimetric Study of Mesoporous SBA-15 Modified for Controlled Valproic Acid Delivery
}

\author{
Liliana Giraldo, ${ }^{1}$ and Juan Carlos Moreno-Piraján ${ }^{2}$ \\ ${ }^{1}$ Departamento de Química, Facultad de Ciencias, Universidad Nacional de Colombia, Bogotá, Colombia \\ ${ }^{2}$ Departamento de Química, Facultad de Ciencias, Grupo de Investigación en Sólidos Porosos y Calorimetría, \\ Universidad de los Andes, Bogotá, Colombia
}

Correspondence should be addressed to Juan Carlos Moreno-Piraján; jumoreno@uniandes.edu.co

Received 4 July 2012; Revised 7 October 2012; Accepted 7 October 2012

Academic Editor: Jose Alberto Pereira

Copyright (C) 2013 L. Giraldo and J. C. Moreno-Piraján. This is an open access article distributed under the Creative Commons Attribution License, which permits unrestricted use, distribution, and reproduction in any medium, provided the original work is properly cited.

\begin{abstract}
SBA-15 ordered mesoporous silica functionalized with (3-aminopropyl)triethoxysilane (APTES) was used as the carrier for anticonvulsant drug 2-propylpentanoic acid (valproic acid). The surface of SBA-15 containing free silanol groups was modified with 3-aminopropyltriethoxysilane via postsynthetic reaction. Functionalization of the carrier with basic aminopropyl groups resulted in an ionic interaction with acidic valproic acid. The samples of carriers and carrier-drug complexes were characterized by elemental analysis, $\mathrm{N}_{2}$ adsorption, FTIR, and UV spectroscopy. The adsorption of valproic acid on modified mesoporous matrix was proportional to the amount of introduced aminopropyl groups. A thermodynamic study with isothermal titration calorimetry (ITC) was made to characterize the modification and encapsulation of SBA-15 with APTES and valproic acid, respectively. The maximum content of deposited drug in modified SBA-15 was close to $30 \mathrm{wt} . \%$. Tests performed in acidic solution (pH 2.0) showed the best pharmaceutical availability.
\end{abstract}

\section{Introduction}

Controlled drug-delivery systems (DDSs) are one of the most promising applications for human health care and represent an ever-evolving field for biomedical material science [14]. The development of new active molecules and potential treatments, such as gene therapy, is leading to the development of new therapeutic agents and the enhancement of the mechanisms to administer them. Basically, a drug delivery system can be described as a formulation that controls the rate and period of drug delivery (i.e., timerelease dosage) and targets specific areas of the body. Unlike traditional therapies, which show a saw-tooth curve of drug concentration in plasma, DDSs are designed to maintain therapeutic levels during the treatment period $[4,5]$.

Furthermore, the isothermal titration calorimetry (ITC) is now routinely used to directly characterize the thermodynamics of biopolymer binding interactions [6-10]. This is the result of improvements in ITC instrumentation and data analysis software. Modern ITC instruments make it possible to measure heat effects as small as $0.1 \mu \mathrm{cal}(0.4 \mu \mathrm{J})$, allowing the determination of binding constants, $K_{s}$, as large as $10^{8}-10^{9} \mathrm{M}^{-1}$.

The extended use of mesoporous materials as adsorbents of drug agents is due to both its texture and the chemical properties of the surface, which also depend on the original materials and the method used to prepare the mesoporous solid, which can be modified with physical and chemical treatments to improve the adsorbent properties. The factors which influence the encapsulation process in the solution include the SBA-15, the adsorbate, the chemist who prepared the solution, and its temperature [10-12]. The use of isothermal titration calorimetry (ITC) has become the gold standard for the thermodynamic investigation of binding interactions. A total of 623 articles were cited in an ITC literature review in 2007 written by Bjelic and Jelesarov showing the value of the use of ITC [13-16]. When ITC is used to determine the thermodynamic parameters of a binding interaction, typically a ligand is titrated with a receptor. ITC measures the heat of the interactions of each injection and calculates the 
enthalpy change since this takes place at constant pressure. By plotting the enthalpy changes for each injection against the amount of ligand versus receptor, an equilibrium binding association constant $\left(K_{a}\right)$ and the stoichiometry $(n)$ can be modelled from the shape of the curve [14-24].

SBA-15 mesoporous silica has been investigated as the potential drug carrier material due to large surface area, large pore size, thick walls, and easy surface modification $[25,26]$. Some insoluble drugs, such as ibuprofen, nimodipine, itraconazole, and so on, have been applied to control the delivery from SBA-15 into simulated biological fluids [26-29]. Then, the introduction of appropriate organic compounds into SBA-15 has presented excellent results regarding drug release control. The choice of appropriate functionalizing agent can generate the inner channel surface acidic [30], basic [31], as well as hydrophobic [32]. Furthermore, the functionalized surface groups can interact via ionic interactions with desired drug. For example, mesoporous materials modified with amine groups were applied as carriers for adsorption of drugs with acidic character [33]. In contrary, modification of the surface of SBA-15 or MSU with acids (e.g., with carboxylic groups) increases the adsorptive properties of drugs with basic properties [33-36]. For example, valproic acid (VPA) is one of the most widely used anticonvulsants in our country. Serious adverse effects include hepatotoxicity, hyperammonemic encephalopathy, coagulation disorders, and pancreatitis.

The incidence of VPA-associated pancreatitis has been estimated to be $1: 40,000$. The incidence of acute pancreatitis (AP) in children is estimated to be 2-2.7: 100,000 [26]. The literature medical reports say that 11 -year-old boy admitted to hospital with complaints of acute abdomen and diagnosed acute hemorhagic pancreatitis after laparatomy. This has been a of first cases documented case with VPA-associated pancreatitis in Turkey.

It can be noted in the valproic acid structure shown in Figure 1 that the $\mathrm{OH}$ its structure may serve as proton donors to form hydrogen bonds with carriers [30].

Therefore, mesoporous SBA-15 material may be a good candidate for valproic acid adsorption because of its relatively large pore size, abundant hydroxyl groups, and easily modified surface with silanes. In this work, a simple and effective approach has been developed for controlled drug delivery carrier through local surface modification in mesoporous silica SBA-15 with aminopropyl groups.

Moreover, in this work calorimetric measurements are performed to establish the thermodynamics of encapsulation with APTES on SBA-15 and valproic acid.

\section{Experimental}

2.1. Materials. SBA-15 mesoporous silica was synthesized following the procedure introduced in [36]. $2.7 \mathrm{~g}$ of poly(ethylene glycol)-block-poly(propylene glycol)-blockpoly(ethylene glycol) (also known as P123) was dissolved in $65 \mathrm{~mL}$ of $2.5 \mathrm{M} \mathrm{HCl}$ at room temperature, and $10.0 \mathrm{~g}$ of $\mathrm{KCl}$ was added to the solution. Then, $5.7 \mathrm{~g}$ of tetraethyl orthosilicate (TEOS) was added under vigorous stirring.

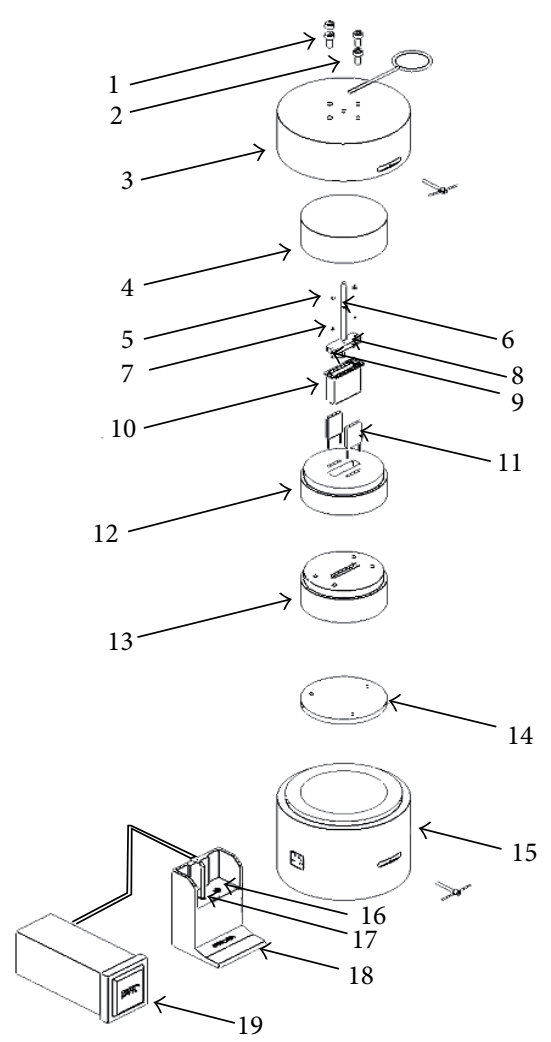

FIGURE 1: Exploded view of the isothermal titration calorimeter: 1, 2: Electronic terminals and support. 3: Superior lid. 4: Internal lid of calorimeter. 5: Tube and extension. 6, 7: Guides of tube. 8: Microcalorimeter lid. 9: Bulb cell. 10: Cell microcalorimetric. 11: Themopiles. 12, 13, 14: Lids inferior. 15: Telon isolated. 16, 17, 18: Titration parts. 19: Controler of titration.

The final reactant molar composition was $0.03 \mathrm{P} 123 / 5 \mathrm{KCl} / 7$ $\mathrm{HCl} / 177 \mathrm{H}_{2} \mathrm{O} / 2$ TEOS. After stirring at room temperature for a day, the mixture was transferred into an autoclave and heated at $110^{\circ} \mathrm{C}$ for $48 \mathrm{~h}$. The product was, then, collected by filtration and washed with both ethanol and water (to remove unreacted $\mathrm{P} 123$ and $\mathrm{KCl}$ ) and dried. The as-made powder was calcined at $620^{\circ} \mathrm{C}$ for $12 \mathrm{~h}$ to remove the organic template.

2.2. Modification of SBA-15 with APTES. $7.0 \mathrm{~g}$ of dry SBA-15 (dried at $110^{\circ} \mathrm{C}$ for $48 \mathrm{~h}$ ) was introduced into $70 \mathrm{~cm}^{3}$ solution containing different amounts of (3aminopropyl)triethoxysilane (APTES) in water-free toluene while continuously stirring. The molar ratio of $\mathrm{SiO}_{2}$ to APTES varied between $1: 25$ and $1: 2$ (Table 1 ). The reaction of SBA-15 with APTES was performed in closed system at $100^{\circ} \mathrm{C}$ for $48 \mathrm{~h}$. After cooling and filtration samples were five-fold washed with toluene $\left(5 \times 250 \mathrm{~cm}^{3}\right)$ and dichloromethane $\left(5 \times 250 \mathrm{~cm}^{3}\right)$. Samples were next dried for $48 \mathrm{~h}$ at $120^{\circ} \mathrm{C}$ (heating rate $0.5^{\circ} \mathrm{C} / \mathrm{min}$ ). Next, samples were treated $\left(5 \times 200 \mathrm{~cm}^{3}\right)$ with methanol-water solution $(1: 10, \mathrm{v} / \mathrm{v})$ and soaked for $6 \mathrm{~h}$ with this mixture $\left(200 \mathrm{~cm}^{3}\right.$, stirring condition) in order to purify and hydrolyze the possible residue of ethoxyl groups. The carrier was filtered 
TABLE 1: Characterization of modified SBA-15 with aminopropyl groups and the carriers loaded with valproic acid.

\begin{tabular}{lcccccc}
\hline Sample & $\begin{array}{c}\text { Initial molar ratio } \\
\text { APTES SBA-15 }\end{array}$ & $\begin{array}{c}\text { Amount of aminopropyl } \\
\text { group in the carrier } \\
\left(\mathrm{mol}^{\mathrm{b}} \cdot \mathrm{g}^{-1}\right)\end{array}$ & $\begin{array}{c}S_{\mathrm{BET}}\left(\mathrm{m}^{3} \cdot \mathrm{g}^{-1}\right) \\
\begin{array}{c}\text { BJH pore } \\
\text { volume }\left(\mathrm{cm}^{3}\right)\end{array}\end{array}$ & $\begin{array}{c}t \text {-plot micropore } \\
\text { volume }\left(\mathrm{cm}^{3}\right)\end{array}$ & $\begin{array}{c}\text { Average pore } \\
\text { diameter }(\mathrm{nm})\end{array}$ \\
\hline SBA-15 & - & - & 825 & 1.08 & 0.0776 & 6.9 \\
SBA-15-AP(1:25) & $(1: 25)$ & $6.37 \times 10^{-3}$ & 635 & 1.01 & 0.0277 & 6.2 \\
SBA-15-AP(1:15) & $(1: 15)$ & $1.74 \times-10^{-3}$ & 575 & 0.88 & 0.0232 & 6.0 \\
SBA-15-AP(1:5) & $(1: 5)$ & $2.01 \times 10^{-3}$ & 540 & 0.77 & 0.0186 & 5.8 \\
SBA-15-AP(1:1) & $(1: 2)$ & $2.09 \times 10^{-3}$ & 510 & 0.73 & 0.0094 & 5.7 \\
SBA-15-VA & - & - & 640 & 1.04 & 0.0297 & 6.4 \\
SBA-15-AP(1:15)-VA & - & - & 360 & 0.58 & 0.0000 & 6.4 \\
\hline
\end{tabular}

SBA-15 expressed as $\mathrm{SiO}_{2}$.

${ }^{\mathrm{b}}$ Calculated from elemental analysis.

and the excess of solvent was evaporated for $48 \mathrm{~h}$ at $110^{\circ} \mathrm{C}$ (heating rate $0.5^{\circ} \mathrm{C} / \mathrm{min}$ ). These samples were marked as SBA-15-AP(X), where $\mathrm{X}$ corresponds to the molar ratio of $\mathrm{SiO}_{2}$ to APTES used in the synthesis [37].

\subsection{Adsorption of Valproic Acid on SBA-15 Carriers. $5.0 \mathrm{~g}$ of} powdered SBA-15-AP samples modified with APTES (different molar ratio) or non-modified SBA-15 were introduced to $150 \mathrm{~cm}^{3}$ of 2-propanol solution of valproic acid $\left(15 \mathrm{mg} / \mathrm{cm}^{3}\right)$. The adsorption was performed at room temperature for $48 \mathrm{~h}$. Samples were next filtered, dried at room temperature $(48 \mathrm{~h})$, and finally at $70^{\circ} \mathrm{C}$ for another $48 \mathrm{~h}$. The samples (modified with APTES) containing valproic acid were marked as SBA-15-AP(X)-VA. The simple of non-modified SBA15 loaded with valproic acid was described as SBA-15-VA. The amount of adsorbed drug in adsorption equilibrium state was estimated spectrophotometrically as a difference in drug concentration before and after drug adsorption. Before spectrophotometric measurement the samples were centrifuged $(15,000 \times \mathrm{g})$ for $10 \mathrm{~min}$ and the supernatant was diluted with 2-propanol [37]. Measurements of absorbance were performed at $260 \mathrm{~nm}$. Moreover, the total amount of adsorbed valproic acid after drying in all studied samples was calculated from elemental analysis.

2.4. Characterization. X-ray powder diffraction patterns were obtained using a Rigaku Ultima III diffractometer with $\mathrm{Cu} \alpha$ radiation $(k=1.5418 \AA)$ and operating at $40 \mathrm{kV}$ and $44 \mathrm{~mA}$. All XRD patterns were collected in the $3 \mathrm{~h}$ range between $0.5^{\circ}$ and $3^{\circ}$ with a scanning rate of $0.01^{\circ} / \mathrm{min}$. The textural properties of the samples were measured via nitrogen adsorption isotherms at $-196^{\circ} \mathrm{C}(77 \mathrm{~K})$ using a IQ2 sortometer (Quantachrome Inc. USA, Boynton Beach, FL). Prior to each adsorption measurement, the SBA-15 and grafted samples were each degassed under vacuum for $12 \mathrm{~h}$ at $250^{\circ} \mathrm{C}$ and $110^{\circ} \mathrm{C}$, respectively. The total surface area $S_{t}$, external surface area $S_{\text {ext }}$, and primary mesopore volume $V_{p}$ of the samples were calculated using the as-plot method [38]. Pore size distributions (PSD) were calculated from the desorption branch of the $\mathrm{N}_{2}$ isotherm data using the BarretJoyner-Halenda (BJH) method applying the Kruk-JaroniecSayari correction [39]. Images of the materials particles were obtained using a JEOLJSM-6930 scanning electron microscope (SEM) operating with a secondary electron detector and an accelerating voltage of $15 \mathrm{kV}$.

FT-IR spectra were obtained in a Nicolet 6700 FT-IR instrument loaded with a Praying Matins attachment operated at ambient conditions. Powder samples were analyzed at $4 \mathrm{~cm}^{-1}$ resolution and average of over 400 scans in the absorption band range of $4000-400 \mathrm{~cm}^{-1}$.

\subsection{Description of the Newly Built Isothermal Titration} Calorimeter (ITC). We have modified our adsorption calorimeter [6-24] Figure 1 shows a complete exploded view of the calorimeter. It can work either as an adsorption or an isothermal titration calorimeter, making this versatile and new equipment. Its design is not very common and has not been previously reported in the literature. In this design we changed the calorimetric adsorption unit for a complete unit that allows the shots to take the action by titration. This is the main change, which led to slight changes in the main body of microcalorimeters, which are described below. A detailed view from the inside of the equipment to the exterior of the calorimeter is shown in Figure 1. In the diagram, Part No. 10 corresponds to the calorimetric cell made of stainless steel, which is embedded inside a large aluminium block that acts as a heat sink (4 and 12). Due to its thermal diffusion coefficient, the heat sink allows rapid heat conduction to the surroundings of the calorimeter. For this calorimeter, the nylon block (2 and 15) surrounding the equipment permits the rapid stabilisation of temperature. The thermal effects are sensed through the two thermopiles connected in series to increase the sensitivity of the microcalorimeter (11) (Thermoelectric Modules (peltier elements) are made of Bismuth Telluride alloys). These thermoelements generate a voltage signal through feedback, which is proportional to the heat flow produced in the cell. This thermoelectric potential is recorded by means of a 6.5 digit Agilent multimeter (model 34349) which is connected to a computer through an RS-232 interface. The upper part of the adsorption calorimeter consists of a nylon piece, which acts as a lid and at the same time has a conical device divided into two parts which permits the reception of the vial that contains the porous solid without leaving any empty space inside (1,2 and 6). 


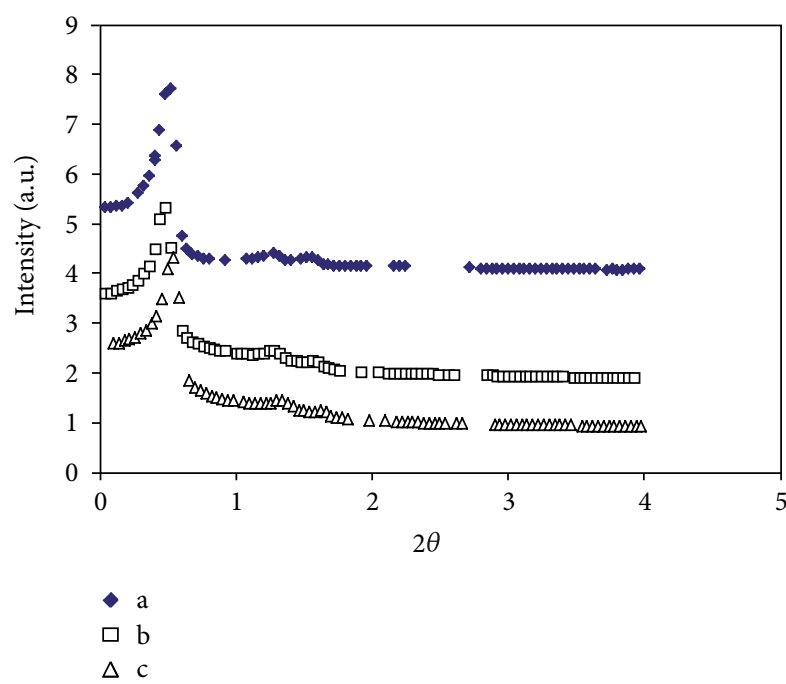

FIGURE 2: XDR diffraction patterns (small angle) of SBA-15 loaded with valproic acid. (a) SBA-15-(1:15)-VA; (b) SBA-15-VA; (c) SBA15.

2.6. Measurement with the ITC on SBA-15 Modified with APTES and the Encapsulation with Valproic Acid. The complete measurement process was fully automated with the aid of a personal computer that was also the controller element in the feedback power loop. After cleaning the vessel, the injection system was sealed with the titrant reactant solutions of APTES (in toluene) in other experiments with valproic acid in solutions buffered. Then, the adsorbent (SBA-15) to be titrated was placed (suspended in buffer) in the sample vessel. Buffer distilled water, acid, or basic solutions was put into the reference vessel for use as blank. The time required to reach thermal equilibrium was about $20 \mathrm{~min}$. At that moment, the stirring system was switched on and after a waiting period of about $20-30 \mathrm{~min}$, a good baseline was obtained. At this instant, the microcalorimeter was ready to carry out the experiment. It is worth indicating that at all times, the vessel contents were stirred and, therefore, an evaluation of the heat due to stirring was not needed. The software program stored all of the required parameters for each experiment run: parameters related to data acquisition (gain, channel, and sample period for the A/D converter, total measure time and baseline offset), with the compensation system (control parameters, depending on the control type: proportional, derivative, and integral) and with the injection system (injection number, injection volume, velocity, and time interval between injections). The recorded data were saved and collected automatically using the data acquisition and analysis software for calorimetry developed in our laboratory (ITC) in a program developed on a MatLab platform (DA-ITC).

\section{Result and Discussion}

3.1. Characterization of Mesoporous Carriers. Data presented in Table 1 as well as the diffraction pattern shown in Figure 2 indicate that the parent, non-modified material represents typical mesoporous SBA-15 structure (pattern a). The lowangle XRD patterns of SBA-15 material show a well resolved peaks assigned to ( 1000$),\left(\begin{array}{lll}1 & 1 & 0\end{array}\right)$ and $\left(\begin{array}{lll}2 & 0 & 0\end{array}\right)$ reflexes characteristic to the hexagonal ordered structure [40]. The properties of these materials are consistent with the data described in the literature [3-41].

The post-synthetic modification of SBA-15 with APTES was realized in the reaction of free silanol groups with ethoxysilanes and resulted in attachment of aminopropyl functional groups [28]. The amount of these groups attached to SBA-15 matrix was calculated from elemental analysis and varied between $6.37 \times 10^{-4}$ and $2.09 \times 10^{-3} \mathrm{~mol}$ of functional groups per gram of the carrier (Table 1). The amount of aminopropyl group in the carrier reached saturation when the APTES: $\mathrm{SiO}_{2}$ molar ratio was lower than 1:5 (compare data in Table 1). This effect resulted from the partial replacement of free silanol groups in SBA-15 channels by modifying agent, therefore maximum of loaded aminopropyl groups was established for molar ratio $1: 5$. It is a consequence of the large molecule size of modifying agent (with aminopropyl chain) shielding close free silanol groups [30-43]. The XRD measurements (Figure 2, pattern b) confirm the hexagonal array of modified material.

Figure 3 shows the nitrogen adsorption-desorption isotherms of non-modified and modified SBA-15 whereas data in Table 1 present details of the textural parameters. In all cases the BET surface area, pore volume, pore size distribution (see side in Figure 3), and microporosity of modificated samples were reduced after modification with APTES. The sample containing the highest amount of aminopropyl groups [SBA-15-AP $(1: 2)$ ] showed reduction of BET surface area, pores volume and micropores volume by $38 \%$, $34 \%$ and $92 \%$, in comparison with non-modified SBA- 15 . The sharp shape of adsorption-desorption hysteresis loop (at $P / P^{0}$ from 0.60 to 0.85 ) is indicative for narrow mesopore size distribution of synthesized SBA-15 and modified materials [42-51]. The blockage of SBA-15 channels and especially of micropores by APTES is demonstrated by lower amounts of nitrogen adsorbed (Figure 3 ). Moreover, the shape of hysteresis loop and its position $\left(P / P^{0} 0.5-0.8\right)$ were changed in comparison to SBA-15 and SBA-15-AP carriers. The similar effect was also described by Tang et al. [45] during adsorption of erythromycin on functionalized mesoporous matrix. The analysis of pore size and micropore volume proved that the adsorbed drug is deposited inside the mesoporous and microporous channels. These observations are compatible with the results reported by $\mathrm{Qu}$ et al. [48], Tang et al. [45] and Tang et al. [49] describing adsorption of other drugs on modified and non-modified SBA-15 and MCM-41 mesoporous materials.

The Figure 4(a) shows the particles SBA-15 synthesized that exhibit typical shapes and haves diameters ca. $6 \mu \mathrm{m}$. After incorporation of APTES into the SBA-15 modified (Figure $4(\mathrm{~b}))$, the channels are more thicker and the form change.

3.2. Valproic Acid Adsorption. The scheme presenting interaction of valproic acid (carboxylic acid) with basic aminopropyl-functionalized mesoporous silica is shown 


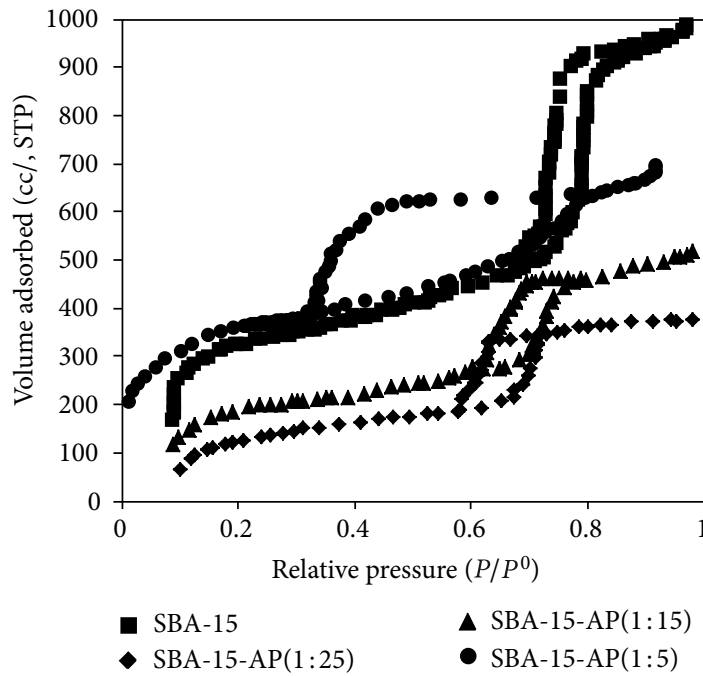

(a)

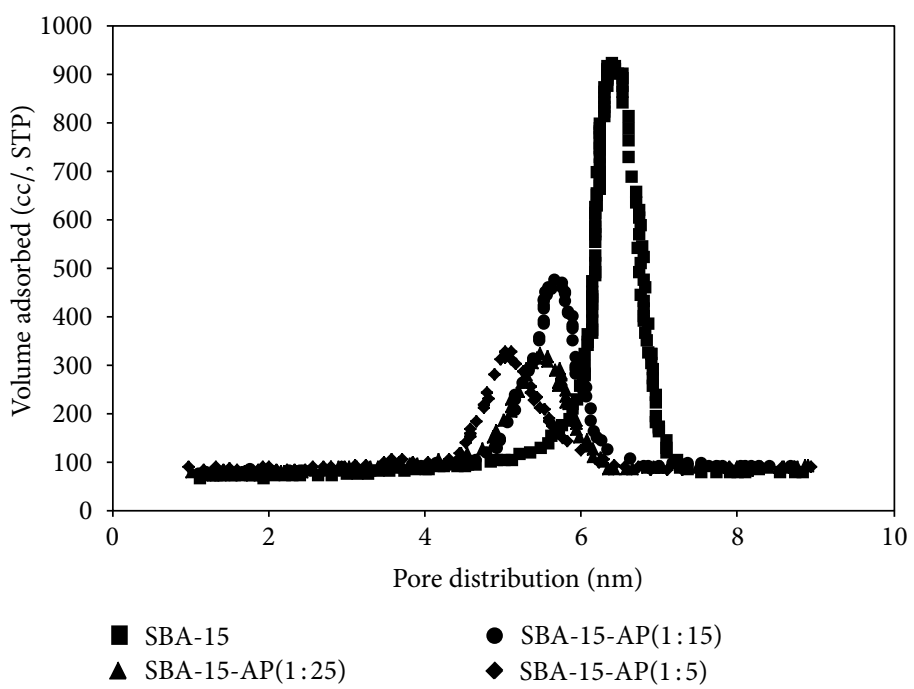

(b)

FIgURE 3: $\mathrm{N}_{2}$ adsorption-desorption isotherms $\left(-196^{\circ} \mathrm{C}\right)$ of SBA-15 modified with APTES: (a) — SBA-15; (b) • SBA-15-AP(1:25); (c) $\Delta$ SBA-15-AP(1:15); (d) $\boldsymbol{\nabla}$ SBA-15-AP(1:5). Pore distribution.

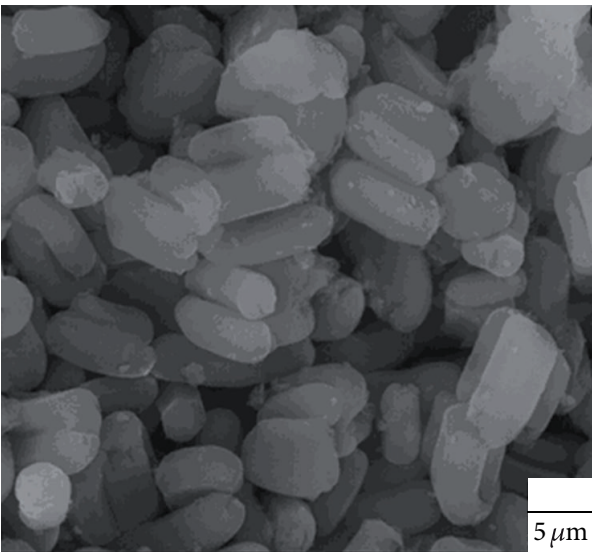

(a)

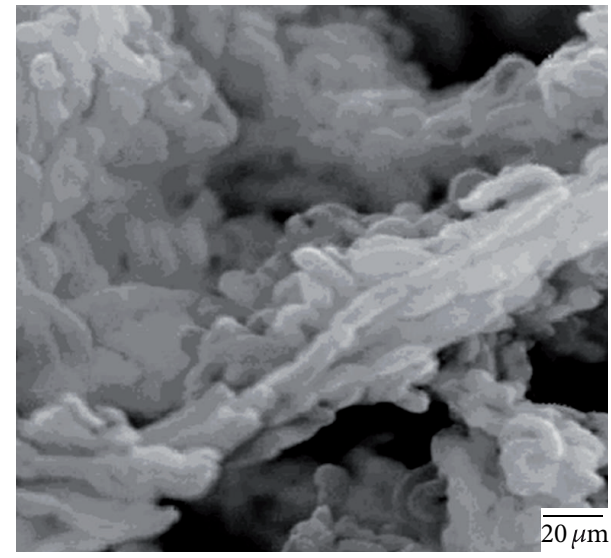

(b)

FIGURE 4: SEM images of (a) SBA-15; (b) SBA-15-AP.

in Figure 5. Vallet-Regí et al. [44] indicate that in polar solvents such as 2-propanol used in this study the ionic interaction between drug and carriers was possible. The results of elemental analysis and spectrophotometric analysis in adsorption equilibrium state of valproic acid-containing sample are shown in Table 2; these calculations have been perfomed as reported in the literature by Zhao et al. [36]. The amount of valproic at equilibrium is proportional to the contents of aminopropyl groups located in modified SBA- 15 .

Table 2 is in good agreement with the literature data $[25,37]$. This is demonstrated by the amount ( 35wt.\%) of adsorbed valproic acid in samples fully saturated with APTES. The differences in amount of adsorbed valproic acid measured by spectrophotometric method and elemental analysis arise from the incomplete separation of the carrier suspension and the drug solution during adsorption experiments. Slightly higher values of adsorbed valproic acid measured by elemental analysis suggest that incomplete elimination occurred after filtering as has been suggested by others authors [37]. The complete elimination of drug solution from the mesoporous capillaries of SBA-15 is very difficult [46].

Figure 6 shows the FTIR spectra of the modified and non-modified SBA-15 carrier before and after valproic acid adsorption. Adsorption of valproic acid on modified SBA-15 resulted in disappearance of the absorption band at $1670 \mathrm{~cm}^{-1}$ characteristic to carbonyl stretching vibrations in carboxylic groups in adsorbed drug ((SBA15-VA(b)) [36-51]. Moreover, after drug adsorption on amino-modified SBA-15 (SBA-15-AP-(1:15) (c)) characteristic band at $1600 \mathrm{~cm}^{-1}$ corresponding to stretching vibrations of ionized carboxylic groups was observed in the Figure $5[37,46]$. These observations confirm the ionic character of the drug-carrier interaction [31,37]. The appearance of 
TABLE 2: Adsoption of valproic acid on SBA-15 material modified with with APTES.

\begin{tabular}{|c|c|c|c|c|c|}
\hline \multirow[b]{2}{*}{ Sample } & \multirow{2}{*}{$\begin{array}{l}\text { Amount aminopropyl } \\
\text { group in the carrier } \\
(\mathrm{mol} / \mathrm{g})^{\mathrm{a}}\end{array}$} & \multirow{2}{*}{$\begin{array}{l}\text { Valproic adsorption } \\
\qquad(\mathrm{wt} \%)^{\mathrm{b}}\end{array}$} & \multicolumn{3}{|c|}{ Elemental analysis } \\
\hline & & & $\begin{array}{l}\text { Amount of } C \text { before } \\
\text { drug adsorption (wt } \%)\end{array}$ & $\begin{array}{c}\text { Amount of } C \text { after drug } \\
\text { adsorption (wt } \%)\end{array}$ & $\begin{array}{c}\text { Amount of } \\
\text { valproic (wt } \%)\end{array}$ \\
\hline SBA-15-AP $(1: 25)$-VA & $6.37 \times 10^{-3}$ & 10.34 & 5.43 & 14.77 & 14.23 \\
\hline SBA-15-AP $(1: 15)-V A$ & $1.74 \times-10^{-3}$ & 17.89 & 7.98 & 21.87 & 20.12 \\
\hline SBA-15-AP $(1: 5)-\mathrm{VA}$ & $2.01 \times 10^{-3}$ & 21.78 & 9.34 & 24.67 & 23.87 \\
\hline SBA-15-AP (1:2)-VA & $2.09 \times 10^{-3}$ & 24.56 & 9.55 & 26.45 & 24.45 \\
\hline SBA-15-VA & - & 6.45 & 0.00 & 7.56 & 9.12 \\
\hline
\end{tabular}

a Calculated from elemental analysis, before drug adsorption.

${ }^{\mathrm{b}}$ Calculated from spectrometric analysis (in the state of adsorption equilibrium). The amount of valproic acid was calculated from the formula $\% \mathrm{VA}=\left\{\left[\left(C_{0}-\right.\right.\right.$ $\left.\left.\left.C_{1}\right) \times V\right] /\left[W+\left(C_{0}-C_{1}\right) \times V\right]\right\} \times 100 \%$, where: \% vA is amount of valproic acid; $C_{0}$ is initial concentration of valproic acid; $C_{1}$ is concentration of drug after adsorption process; $V$ is volume of drug solution; $W$ is weight of the carrier. The concentration of valproic acid was estimated spectrophotometrically.
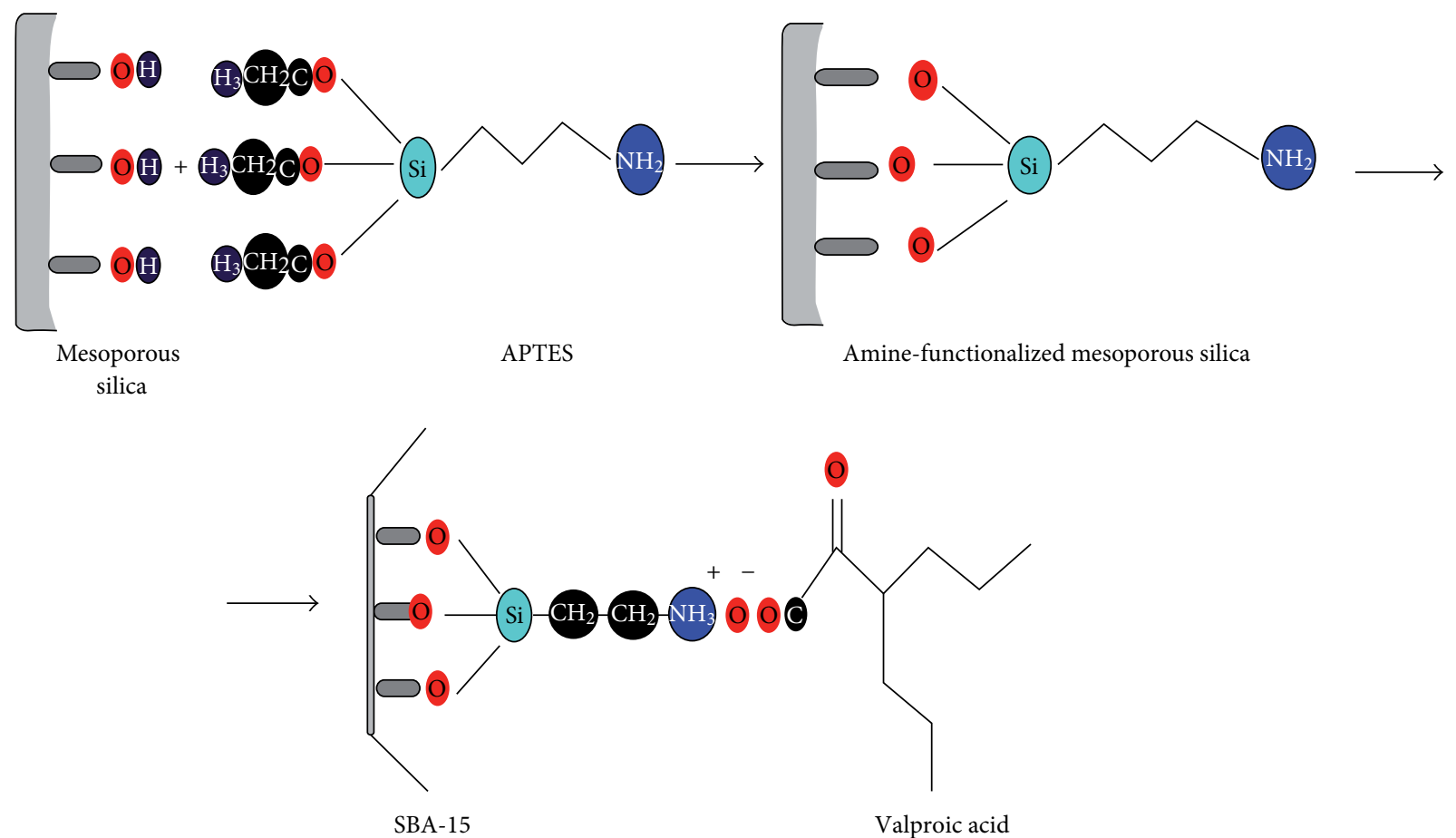

FIGURE 5: Interaction between SBA-15, APTES, and valproic acid.

absorption bands at $1462 \mathrm{~cm}^{-1}$ and $1680 \mathrm{~cm}^{-1}$ in samples loaded with valproic acid additionally (SBA-15-AP-(1:15)$\mathrm{VA}(\mathrm{d})$ ) confirm the presence of aromatic stretching C-C vibrations (Figure 6) and stretching vibrations of carbonyl related to aromatic rings, respectively $[37,46]$.

3.3. Valproic Acid Release. The cumulative release profiles of valproic acid from non-modified and aminopropyl-modified mesoporous SBA-15 in various solutions (water, $\mathrm{pH} 2.0$ hydrochloric acid buffer, $\mathrm{pH} 5.0$ acetic buffer, $\mathrm{pH} 9.0$ phosphate buffer) are shown in Figures 7(a) and 7(b). Although the final pharmaceutical availability (80-95\%) of valproic acid (after $24 \mathrm{~h}$ ) from pure SBA-15 (Figure 7(a)) was similar in all samples it should be noticed that the shape of these curves was different. Valproic acid is a drug with weak acidic properties $(\mathrm{pKa}=4.7)$, poorly soluble in water, therefore its release from non-modified SBA-15 in alkaline phosphate buffer was faster in comparison to acidic medium ( $\mathrm{pH} 2.0$ hydrochloric acid buffer, pH 5.0 acetic buffer) or water $(\mathrm{pH} \sim 7.0)$. The $\mathrm{pH}$ increase results in ionization of valproic acid carboxylic groups and in consequence the higher its solubility. Similar results were observed by Charnay et al. [51] in the work describing ibuprofen release from MCM41 in various media and and Moritz and Łaniecki [37] in the work ketoprofen on SBA-15. It should be noticed that all of the samples exhibited prolonged valproic acid release from mesoporous matrix due to the limited diffusion of this drug from mesoporous and microporous channels. The release profiles of valproic acid adsorbed on aminopropyl-modified SBA-15 are shown in Figure 7(b). Due to the strong ionic 


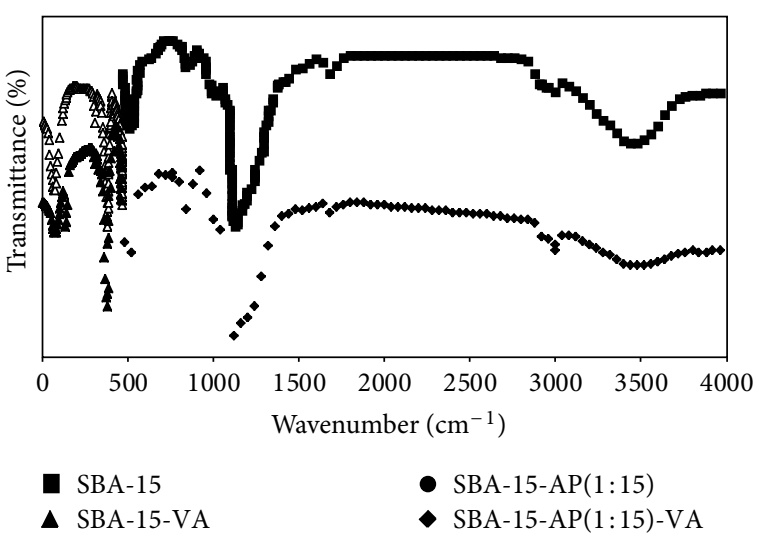

FIGURE 6: FTIR spectra of (a) SBA-15; (b) SBA-15-VA; (c) SBA-15$\operatorname{AP}(1: 15)$; (d) SBA-15-AP( $1: 15)-V A$.

interaction of acidic valproic acid on the basic silica carrier the lowest release of the drug was observed in water. The pharmaceutical availability after $24 \mathrm{~h}$ reached is of $50 \%$ of adsorbed drug, which is of the highest reported about this type of work reported in the literature for example by Moritz and Łaniecki [37].

The highest pharmaceutical availability of valproic acid after $12 \mathrm{~h}(95 \%)$ was observed for SBA-15-AP(1:15)-VA sample released in hydrochloric acidic buffer in comparison to other buffers. Although the release rate from this sample was initially the good (after $1 \mathrm{~h}-40 \%$ ) the final effect was much better than with the other buffer solutions $(32 \%$ at $\mathrm{pH}-5.0$ and $35 \%$ at $\mathrm{pH}-9.0$ ). This effect results from shifted ionic equilibrium in acidic medium $(2.0 \mathrm{pH})$ and from precipitation of free acidic valproic. Significant content of valproic in SBA-15-AP(1:15)-VA sample (above $30 \mathrm{wt} . \%$ ) caused local saturation of valproic solution and its precipitation in acidic environment. The possibility of drug precipitation from mesoporous matrix was considered by Moritz and Łaniecki [37]. In the next step the precipitated valproic was transformed into soluble form and simultaneously further amounts of drug were released from the pores of the support. Final release of valproic (after $24 \mathrm{~h}$ ) at $\mathrm{pH} 2.0$ and $\mathrm{pH} 5.0$ was slightly lower in comparison to hydrochloric acid buffer and was equal to 80 and $90 \%$ of the drug in the sample, respectively.

The proposed mechanism of drug release in acidic or basic media is shown in Figure 8. However, further studies are required to prove or to reject the proposed mechanism.

\subsection{Analysis of Calorimetric Data: Fixation of APTES onto} SBA-15 and the Encapsulation of Valproic Acid. ITC data were collected automatically using the data acquisition and analysis software for calorimetry developed in our laboratory (ITC) in a program developed on a MatLab platform (DAITC). All data were corrected for the heat of dilution by subtracting the heat remaining after the saturation of binding sites on the adsorbent prior to further data analysis. Data were fitted using a nonlinear least-squares algorithm using a single-site or two-site binding model employed by the
TABLE 3: Thermodynamic parameters of phenol and catechol to activated carbon at $25^{\circ} \mathrm{C}$, determined by isothermal titration calorimetry (ITC).

\begin{tabular}{lcccc}
\hline Compound & $\Delta G$ & $\Delta H$ & $\Delta S$ & $n$ \\
& $(\mathrm{~kJ} / \mathrm{mol})$ & $(\mathrm{kJ} / \mathrm{mol})$ & $(\mathrm{J} / \mathrm{K} \cdot \mathrm{mol})$ & $(\mu \mathrm{mol} / \mathrm{g})$ \\
\hline \multirow{3}{*}{ SBA-15-AP } & -45.6 & -34.7 & -198.5 & 18 \\
& -41.3 & -39.8 & -239.6 & 22 \\
& -36.5 & -43.9 & -257.5 & 27 \\
SBA-15-AP(1:15)-VA & -28.9 & -25.6 & -141.2 & 5 \\
\hline
\end{tabular}

DA-ITC software that accompanies the calorimeter built by us. Fitting the theoretical data to the experimental data yielded the stoichiometry $(n)$ as the amount of adsorbate (solutions of APTES, and valproic acid) per gram adsorbent $(n / g)(S B A-15)$ or $\mu \mathrm{mol}$ of adsorbate/gram adsorbent, the equilibrium binding association constant $\left(K_{a}\right)$, and the reaction enthalpy change $\left(\Delta H_{r}^{\circ}\right)$ of the reaction, that is, when the data is worked up, the recorded differential power is integrated over each injection time interval, and the molar ratio of titrant to titrant versus $\Delta H$ is plotted for each injection event.

Ideally, this data can be fit to a sigmoidal-shaped curve from which the enthalphy of binding $\Delta H$, the equilibrium constant $K_{a}$, and the stoichiometric factor $n$ can be extracted (Figure 9). $\Delta H$ is simply the extrapolated $y$-axis intercept, $n$ is the amount of adsorbate (phenol or cathecol) per gram adsorbent $(n / \mathrm{g})$ or $\mu \mathrm{mol}$ of adsorbate/gram adsorbent at the curve's inflexion point, and $K_{a}$ is obtained from the slope of the curve at the inflexion point.

The changes in the reaction free energy $\left(\Delta G_{r}^{\circ}\right)$ and entropy $\left(\Delta S_{r}^{\circ}\right)$ were calculated using (1). Errors in $\Delta H_{r}^{\circ}$ and $K_{a}$ were obtained as the standard deviations of at least five experiments:

$$
\Delta G_{r}^{\circ}=-\mathrm{RT} \ln K_{a}=\Delta H_{r}^{\circ}-T \Delta S_{r}^{\circ} .
$$

3.5. Binding of APTES and Valproic Acid to SBA-15. The typical thermograms (Figure 9(a)) clearly show that APTES binds to four distinct binding sites on the SBA-15, corresponding to the chemical bonds of each of the $\mathrm{OH}$ groups of SBA-15 with EtO- of APTES, one strong $(\Delta G=-45.6 \mathrm{~kJ} / \mathrm{mol}$ for one $-\mathrm{OH}$ group) and the fourth low value relatively weak $(\Delta G=-30.2 \mathrm{~kJ} / \mathrm{mol}$ for the other $-\mathrm{OH})$ (Table 3$)$.

Figure 9(b) (enthalpy in terms of micromoles of valproic acid on SBA-15-AP( $1: 5)$ expressed in grams) for the valproic acid in solution shows an abrupt change that is characteristic of simple interaction between a single- $\mathrm{NH}_{2}$ group (of SBA15-APTES) and the adsorbent (valproic acid), but when the adsorbate or adsorbent has several functional groups, such as $-\mathrm{NH}_{2}$ in of SBA-15, a competition is generated on the adsorbent surface, producing an initially strong enthalpic peak, and then smooth curves, which is associated with the presence of six binding sites on SBA-15. On the other hand, the valproic acid site shows only one chemical bond that we associated with the interaction of the $-\mathrm{Si}-\left(\mathrm{CH}_{2}\right)_{3}-$ group on 


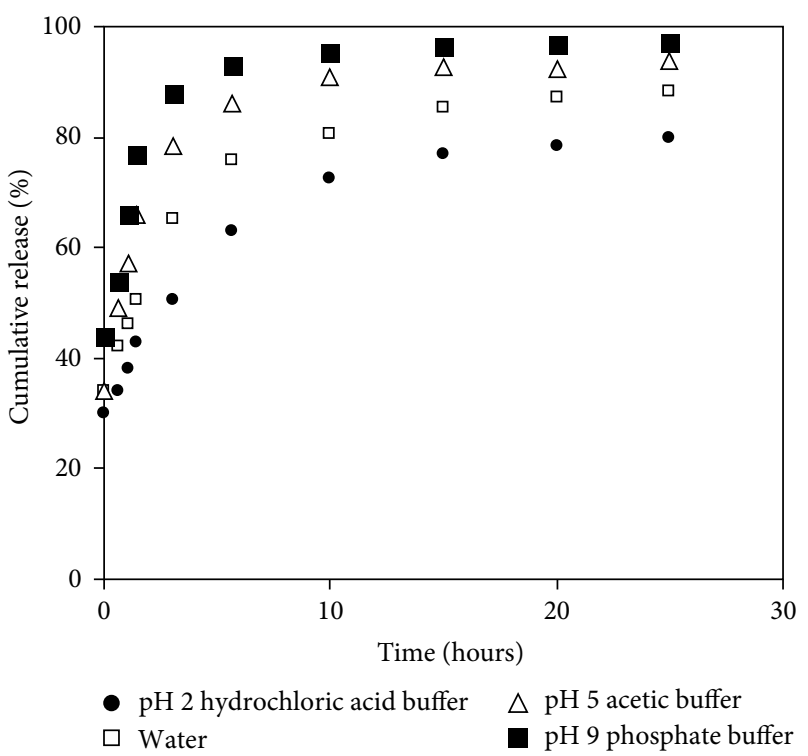

(a)

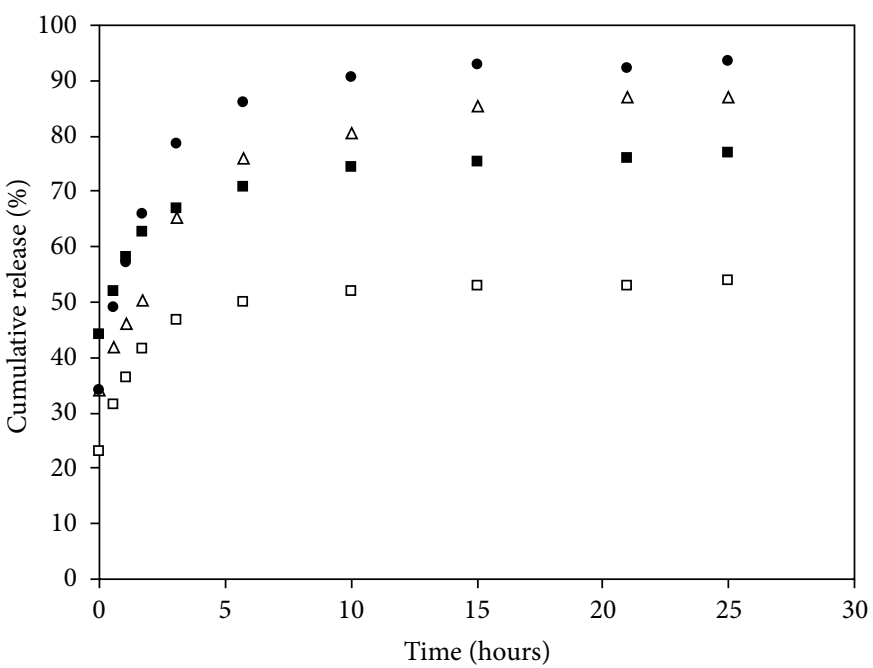

- $\mathrm{pH} 2$ hydrochloric acid buffer $\triangle \mathrm{pH} 5$ acetic buffer $\square$ Water
- $\mathrm{pH} 9$ phosphate buffer

(b)

FIgURE 7: Profiles of cumulatives release of valproic acid from (a) non-modified SBA-15-VA sample and (b) APTES-modified SBA-15AP(1:15)-VAP sample.

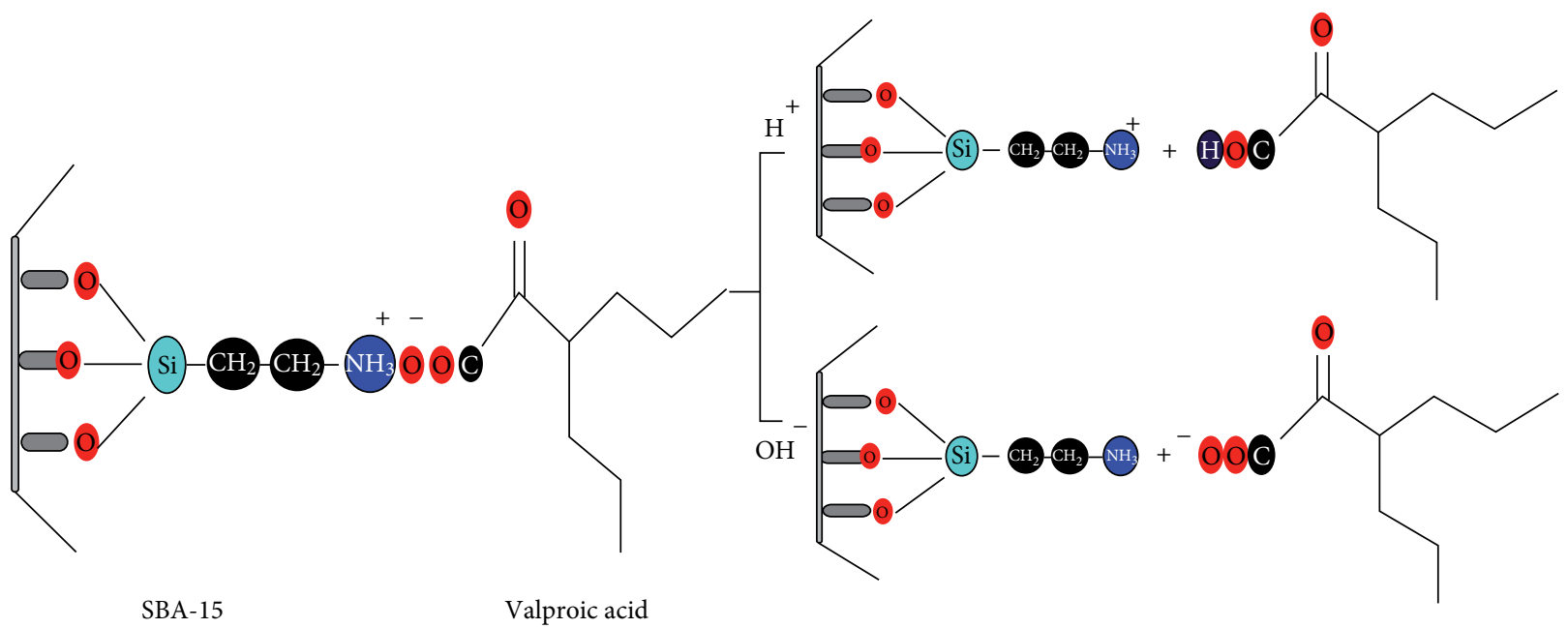

FIGURE 8: Drug mechanism release of valproic acid from aminopropyl-modified SBA-15 in acidic and basic media.

SBA-15-AP; a value of $\Delta G=-28.9 \mathrm{~kJ} / \mathrm{mol}$ was obtained. Thermodynamic studies of this type using ITC have not yet been reported. This study provides a new perspective and a distinctive contribution to this field of research. On the other hand the values for the thermodynamic functions (enthalpy, free energy, and entropy) were negative, showing that the modification of the SBA-15 with APTES and the encapsulation of SBA-15-AP with valproic acid are spontaneous. When comparing the values thermodynamic obtained between SBA-15-AP and SBA-15-AP(1:15)-VA, ITC calorimetry was able to differentiate the results of the titration, as well as the effects of the presence of each of the $\mathrm{OH}$ groups of the SBA-15 and the interaction with APTES and the interaction of groups $-\mathrm{NH}_{2}$ and $-\mathrm{COOH}$ of valproic acid. In the case of SBA-15/APTES system, the presence of different $\mathrm{OH}$ groups of SBA-15 determines six different values of enthalpy $(-26.4 \mathrm{~kJ} / \mathrm{mol}$ and $-38.8 \mathrm{~kJ} / \mathrm{mol})$ which shows the different strength with which the $-\mathrm{OH}$ is attached inside the pores of SBA-15. This research has established the equilibrium constants of the adsorption of the SBA-15-APVA and SBA-15-AP systems under study, which show that the reaction between the SBA-15 and APTES and SBA-15-AP and valproic acid are is very stable.

Using the computer built (ITC) is possible to evaluate the isosteric heat of APTES and valproic acid on SBA-15 at constant coverage by varying the temperature using the temperature controller that was designed for this purpose. The titration calorimetry is useful in studies of chemical 

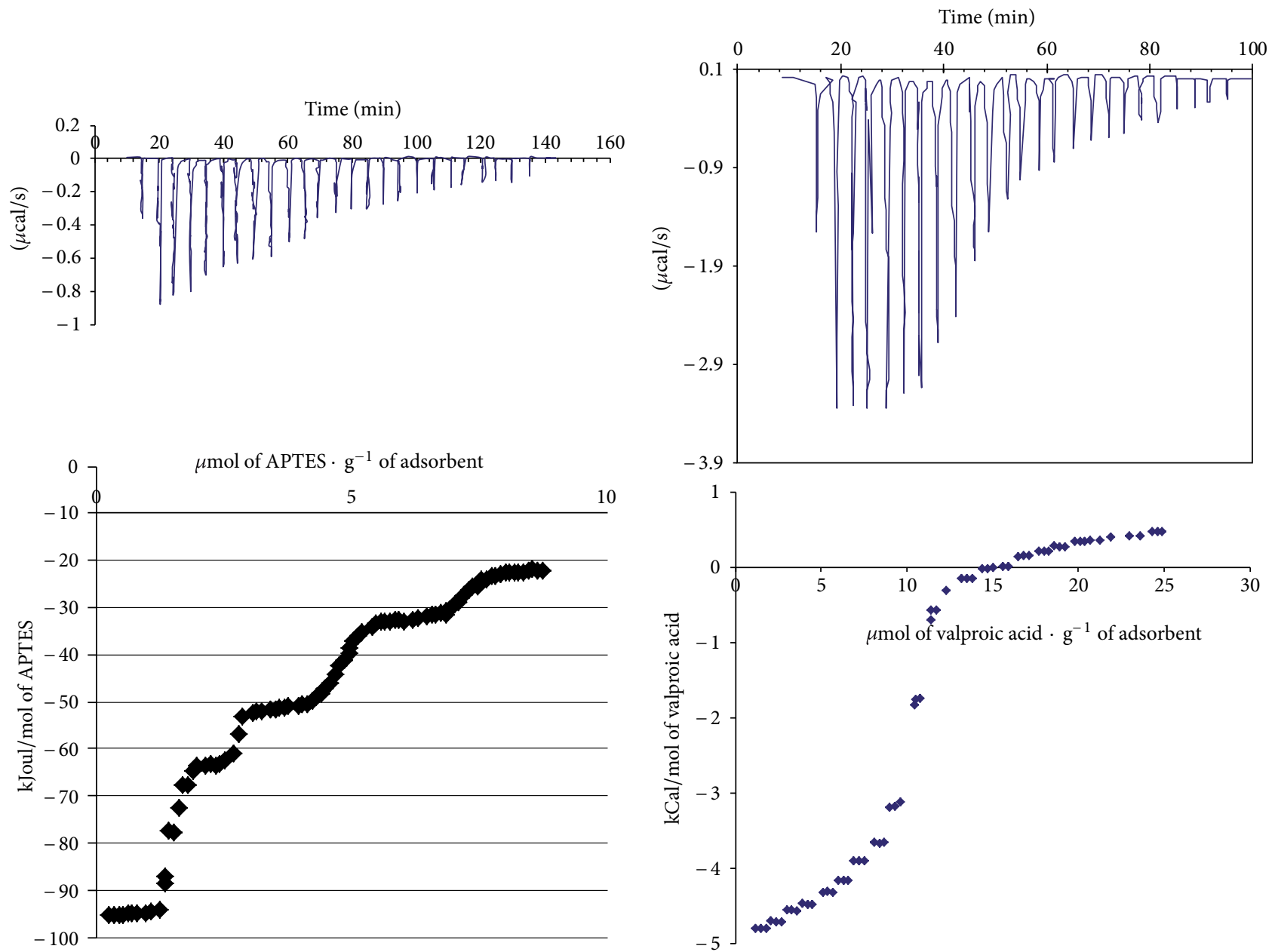

(a)

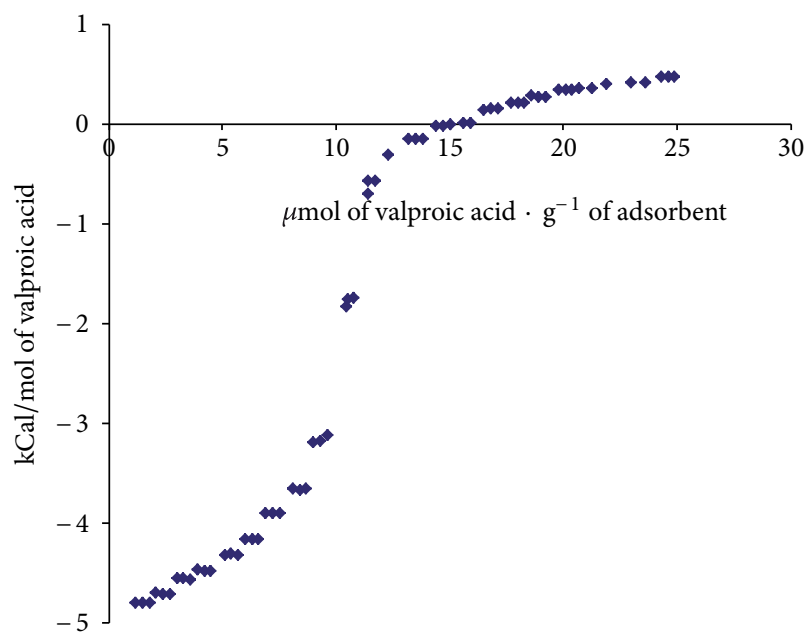

(b)

FIGURE 9: Thermograms for the titration of (a) APTES and (b) valproic acid solution on SBA-15-AP(1:15) at $25^{\circ} \mathrm{C}$.

kinetics, determination of reaction mechanisms, and in studies of structural rearrangements of the adsorbate upon adsorption/partition and the excluded water molecules or ions in the bulk solvent; the ITC also analyze of exclusion of water or ions surrounding the adsorbate and the hydrophobic interactions between the adsorbate and the hydrophobic parts of the adsorbent sites.

\section{Conclusion}

SBA-15 mesoporous material, both in non-modified or modified forms, can be used as the carrier for adsorption of acidic drug such as valproic. The modification of mesoporous and microporous channels of SBA-15 with 3-aminopropyl group leads towards formation of carriers with surface basic properties. High amount of adsorbed drug ( 30 wt.\%) showed that modified SBA-15 could be a suitable carrier for valproic. The valproic acid adsorption on the non-modified and modified carrier contributed to its increased thermal stability what can be a great advantage in drug formulation. Drug release rate was dependent on $\mathrm{pH}$ value of dissolution medium. Obtained results give promising perspectives for future application of mesoporous materials in drug delivery systems. The use of ITC allowed for the determination of the thermodynamics of APTES and valproic acid reaction on SBA-15, which took place at a different-binding site that was relatively strong. The thermodynamic variables showed that adsorption was a spontaneous process; additionally, the goal of this research was to show that with this technique (ITC), is possible differentiate the adsorption of APTES and valproic acid on SBA-15.

\section{Acknowledgments}

The authors wish to thank the Master Agreement established between the Universidad de los Andes and the Universidad Nacional de Colombia and the Memorandum of Understanding entered into by the departments of chemistry of both universities. Additionally, thanks to the special fund "Proyecto Semilla" of the Sciences of Faculty the Universidad de Los Andes, for partial funding of this research. 


\section{References}

[1] V. P. Torchilin, "Recent advances with liposomes as pharmaceutical carriers," Nature Reviews Drug Discovery, vol. 4, no. 2, pp. 145-160, 2005.

[2] J. W. Yoo and C. H. Lee, "Drug delivery systems for hormone therapy," Journal of Controlled Release, vol. 112, no. 1, pp. 1-14, 2006.

[3] M. Malmsten, "Soft drug delivery systems," Soft Matter, vol. 2, no. 9, pp. 760-769, 2006.

[4] M. Vallet-Regí, "Ordered mesoporous materials in the context of drug delivery systems and bone tissue engineering," Chemistry, vol. 12, no. 23, pp. 5934-5943, 2006.

[5] M. Vallet-Regí, F. Balas, and D. Arcos, "Mesoporous materials for drug delivery," Angewandte Chemie, vol. 46, no. 40, pp. 7548-7558, 2007.

[6] O. Vázquez, M. E. Vázquez, J. B. Blanco, L. Castedo, and J. L. Mascareñas, "Specific DNA recognition by a synthetic, monomeric $\mathrm{cys}_{2} \mathrm{His}_{2}$ Zinc-finger peptide conjugated to a minor-groove binder," Angewandte Chemie, vol. 119, no. 36, pp. 7010-7014, 2007.

[7] J. Christensen, L. D. Hansen, and R. M. Izatt, Handbook of Proton Ionization Heats and Related Thermodynamic Quantities, John Wiley \& Sons, New York, NY, USA, 1976.

[8] A. C. Fonseca, S. Jarmelo, J. Canotilho et al., "Thermoanalytical study of Ná-benzoyl-l-argininate ethyl ester chloride," Thermochimica Acta, vol. 527, no. 10, pp. 83-90.

[9] P. J. Gandhi and Z. V. P. Murthy, "Measurement of solubility of mitomycin $\mathrm{C}$ in ethanol-water solutions at different temperatures," Thermochimica Acta, vol. 545, pp. 163-173, 2012.

[10] D. Eatough, E. Lewis, and L. Hansen, "Determination of ÄH and Keq values," in Analytical Solution Calorimetry, K. Grime, Ed., John Wiley \& Sons, New York, NY, USA, 1985.

[11] A. M. Mocanu, C. Moldoveanu, L. Odochian, C. M. Paius, N. Apostolescu, and R. Neculau, "Study on the thermal behavior of casein under nitrogen and air atmosphere by means of the TGFTIR technique," in Thermochimica Acta, vol. 546, pp. 120-126, 2012.

[12] F. Stoeckli, M. V. López-Ramón, and C. Moreno-Castilla, "Adsorption of phenolic compounds from aqueous solutions, by activated carbons, described by the dubinin-astakhov equation," Langmuir, vol. 17, no. 11, pp. 3301-3306, 2001.

[13] Q. Liao, J. Sun, and L. Gao, "The adsorption of resorcinol from water using multi-walled carbon nanotubes," Colloids and Surfaces A, vol. 312, no. 2-3, pp. 160-165, 2008.

[14] M. Ahmaruzzaman and D. K. Sharma, "Adsorption of phenols from wastewater," Journal of Colloid and Interface Science, vol. 287, no. 1, pp. 14-24, 2005.

[15] A. Dabrowski, Z. Hubicki, P. Podkoscielny, and E. Robens, "Selective removal of the heavy metal ions from waters and industrial wastewaters by ion-exchange method," Chemosphere, vol. 56, no. 2, pp. 91-106, 2004.

[16] C. Moreno-Castilla, J. Rivera-Utrilla, M. V. López-Ramón, and F. Carrasco-Marín, "Adsorption of some substituted phenols on activated carbons from a bituminous coal," Carbon, vol. 33, no. 6, pp. 845-851, 1995.

[17] F. Villacañas, M. F. R. Pereira, J. J. M. Orfao, and J. L. Figuereido, "Adsorption of dyes on carbon xerogels and templated carbons: influence of surface chemistry," Adsoprton, vol. 17, pp. 431-441, 2011.
[18] R. J. Falconer, A. Penkova, I. Jelesarov, and B. M. Collins, "Survey of the year 2008: applications of isothermal titration calorimetry," Journal of Molecular Recognition, vol. 23, no. 5, pp. 395-413, 2010.

[19] T. Wiseman, S. Williston, J. F. Brandts, and L. N. Lin, "Rapid measurement of binding constants and heats of binding using a new titration calorimeter," Analytical Biochemistry, vol. 179, no. 1, pp. 131-137, 1989.

[20] A. J. Varma, S. V. Deshpande, and J. F. Kennedy, "Metal complexation by chitosan and its derivatives: a review," Carbohydrate Polymers, vol. 55, no. 1, pp. 77-93, 2004.

[21] I. M. Badawy and E. I. Rabea, "A biopolymer chitosan and its derivatives as promising antimicrobial agents against plant pathogens and their applications in crop protection," International Journal of Carbohydrate Chemistry, vol. 2011, Article ID 460381, 29 pages, 2011.

[22] J. C. Moreno-Piraján and L. Giraldo, "Design, construction, and calibration of an isothermal titration calorimeter and its application in the study of the adsorption of phenolic compounds," Review of Scientific Instruments, vol. 83, no. 1, Article ID 368059, 2012.

[23] V. García-Cuello, J. C. Moreno-Pirajan, L. Giraldo-Gutiérrez, K. Sapag, and G. Zgrablich, "Variation of the noise levels in the baseline of an adsorption microcalorimeter," Journal of Thermal Analysis and Calorimetry, vol. 97, no. 2, pp. 705-709, 2009.

[24] V. García-Cuello, J. C. Moreno-Pirajan, L. Giraldo-Gutiérrez, K. Sapag, and G. Zgrablich, "Adsorption micro calorimeter : DDDesign and electric calibration," Journal of Thermal Analysis and Calorimetry, vol. 97, no. 2, pp. 711-715, 2009.

[25] D. Y. Zhao, J. L. Feng, Q. S. Huo et al., “Triblock copolymer syntheses of mesoporous silica with periodic 50 to 300 angstrom pores," Science, vol. 279, no. 5350, pp. 548-552, 1998.

[26] D. Y. Zhao, Q. S. Huo, J. L. Feng, B. F. Chmelka, and G. D. Stucky, "Nonionic triblock and star diblock copolymer and oligomeric sufactant syntheses of highly ordered, hydrothermally stable, mesoporous silica structures," Journal of the American Chemical Society, vol. 120, no. 24, pp. 6024-6036, 1998.

[27] A. Szegedi, M. Popova, I. Goshev, and J. Mihály, "Effect of amine functionalization of spherical MCM-41 and SBA-15 on controlled drug release," Journal of Solid State Chemistry, vol. 184, no. 5, pp. 1201-1207, 2011.

[28] H. Yu and Q. Z. Zhai, "Mesoporous SBA-15 molecular sieve as a carrier for controlled release of nimodipine," Microporous and Mesoporous Materials, vol. 123, no. 1-3, pp. 298-305, 2009.

[29] R. Mellaerts, K. Houthoofd, K. Elen et al., "Aging behavior of pharmaceutical formulations of itraconazole on SBA-15 ordered mesoporous silica carrier material," Microporous and Mesoporous Materials, vol. 130, no. 1-3, pp. 154-161, 2010.

[30] R. I. Kureshy, I. Ahmad, K. Pathak, N. H. Khan, S. H. R. Abdi, and R. V. Jasra, "Sulfonic acid functionalized mesoporous SBA15 as an efficient and recyclable catalyst for the synthesis of chromenes from chromanols," Catalysis Communications, vol. 10, no. 5, pp. 572-575, 2009.

[31] Z. Luan, J. A. Fournier, J. B. Wooten, and D. E. Miser, "Preparation and characterization of (3-aminopropyl) triethoxysilanemodified mesoporous SBA-15 silica molecular sieves," Microporous and Mesoporous Materials, vol. 83, no. 1-3, pp. 150-158, 2005.

[32] S. A. Mirji, S. B. Halligudi, D. P. Sawant et al., "Adsorption of octadecyltrichlorosilane on mesoporous SBA-15," Applied Surface Science, vol. 252, no. 12, pp. 4097-4103, 2006. 
[33] W. Zeng, X. F. Qian, J. Yin, and Z. K. Zhu, "The drug delivery system of MCM-41 materials via co-condensation synthesis," Materials Chemistry and Physics, vol. 97, no. 2-3, pp. 437-441, 2006.

[34] Q. Tang, Y. Xu, D. Wu, and Y. Sun, "A study of carboxylicmodified mesoporous silica in controlled delivery for drug famotidine," Journal of Solid State Chemistry, vol. 179, no. 5, pp. 1513-1520, 2006.

[35] Q. Yang, S. Wang, P. Fan et al., "pH-responsive carrier system based on carboxylic acid modified mesoporous silica and polyelectrolyte for drug delivery," Chemistry of Materials, vol. 17, no. 24, pp. 5999-6003, 2005.

[36] D. Zhao, J. Sun, Q. Li, and G. D. Stucky, "Morphological control of highly ordered mesoporous silica SBA-15," Chemistry of Materials, vol. 12, no. 2, pp. 275-279, 2000.

[37] M. Moritz and M. Łaniecki, "SBA-15 mesoporous material modified with APTES as the carrier for 2-(3-benzoylphenyl) propionic acid," Applied Surface Science, vol. 258, pp. 7523-7529, 2012.

[38] M. Kruk and M. Jaroniec, "Characterization of modified mesoporous silica using argon and nitrogen adsorption," Microporous and Mesoporous Materials, vol. 44-45, pp. 725-732, 2001.

[39] M. Jaroniec and L. A. Solovyov, "Improvement of the KrukJaroniec-Sayari method for pore size analysis of ordered silicas with cylindrical mesopores," Langmuir, vol. 22, no. 16, pp. 6757-6760, 2006.

[40] M. Kruk, M. Jaroniec, C. H. Ko, and R. Ryoo, "Characterization of the porous structure of SBA-15," Chemistry of Materials, vol. 12, no. 7, pp. 1961-1968, 2000.

[41] V. Meynen, P. Cool, and E. F. Vansant, "Verified syntheses of mesoporous materials," Microporous and Mesoporous Materials, vol. 125 , no. 3, pp. 170-223, 2009.

[42] M. Jaroniec and L. A. Solovyov, "Assessment of ordered and complementary pore volumes in polymer-templated mesoporous silicas and organosilicas," Chemical Communications, no. 21, pp. 2242-2244, 2006.

[43] V. Meynen, P. Cool, and E. F. Vansant, "Verified syntheses of mesoporous materials," Microporous and Mesoporous Materials, vol. 125 , no. 3, pp. 170-223, 2009.

[44] M. Vallet-Regí, F. Balas, and D. Arcos, "Mesoporous materials for drug delivery," Angewandte Chemie, vol. 46, no. 40, pp. 7548-7558, 2007.

[45] Q. Tang, Y. Xu, D. Wu, and Y. Sun, "A study of carboxylicmodified mesoporous silica in controlled delivery for drug famotidine," Journal of Solid State Chemistry, vol. 179, no. 5, pp. 1513-1520, 2006.

[46] J. C. Doadrio, E. M. B. Sousa, I. Izquierdo-Barba, A. L. Doadrio, J. Perez-Pariente, and M. Vallet-Regí, "Functionalization of mesoporous materials with long alkyl chains as a strategy for controlling drug delivery pattern," Journal of Materials Chemistry, vol. 16, no. 5, pp. 462-466, 2006.

[47] E. Pretsch, P. Bühlmann, and C. Affolter, "Structure determination of organic compounds," in Tables of Spectral Data, Springer, Berlin, Germany, 3rd edition, 2000.

[48] F. Qu, G. Zhu, S. Huang et al., "Controlled release of Captopril by regulating the pore size and morphology of ordered mesoporous silica," Microporous and Mesoporous Materials, vol. 92, no. 1-3, pp. 1-9, 2006.

[49] Q. Tang, Yao Xu, Dong Wu et al., "Studies on a new carrier of trimethylsilyl-modified mesoporous material for controlled drug delivery," Journal of Controlled Release, vol. 114, no. 1, pp. 41-46, 2006.
[50] W. Xu, Q. Gao, Y. Xu, D. Wu, and Y. Sun, "pH-Controlled drug release from mesoporous silica tablets coated with hydroxypropyl methylcellulose phthalate," Materials Research Bulletin, vol. 44, no. 3, pp. 606-612, 2009.

[51] C. Charnay, S. Bégu, C. Tourné-Péteilh, L. Nicole, D. A. Lerner, and J. M. Devoisselle, "Inclusion of ibuprofen in mesoporous templated silica: drug loading and release property," European Journal of Pharmaceutics and Biopharmaceutics, vol. 57, no. 3, pp. 533-540, 2004. 

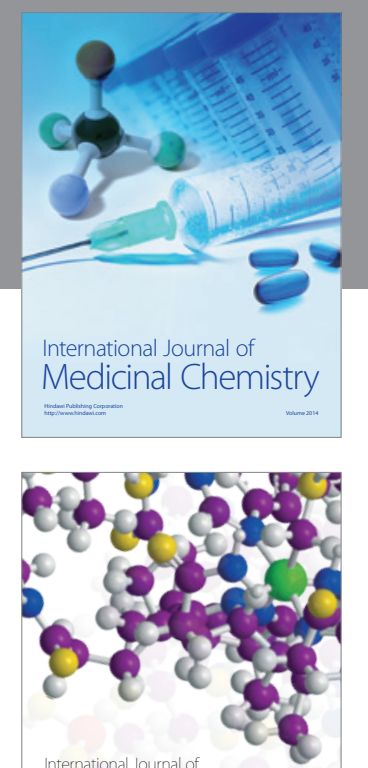

\section{Carbohydrate} Chemistry

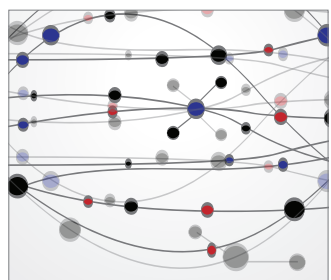

The Scientific World Journal
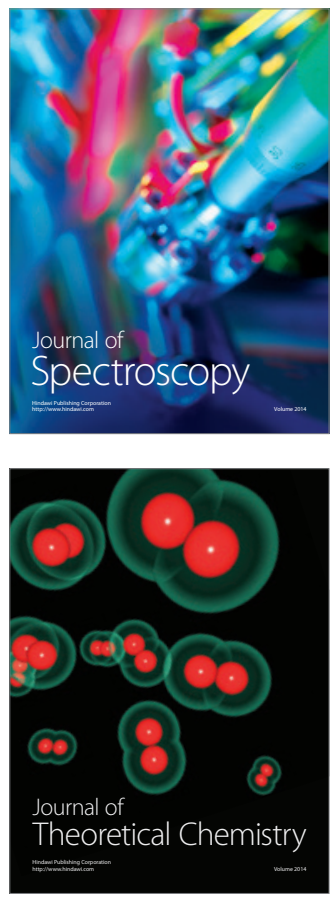
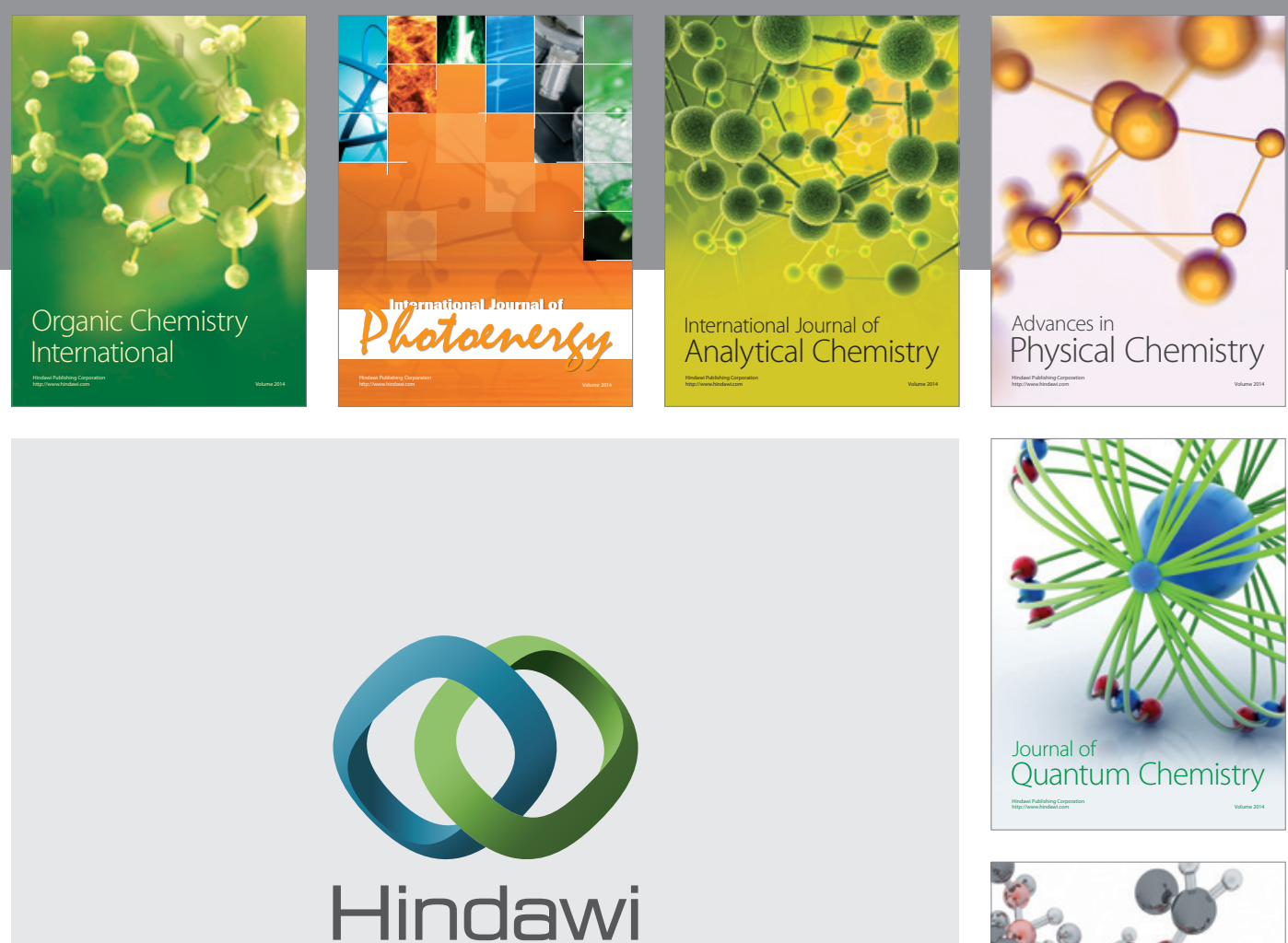

Submit your manuscripts at

http://www.hindawi.com

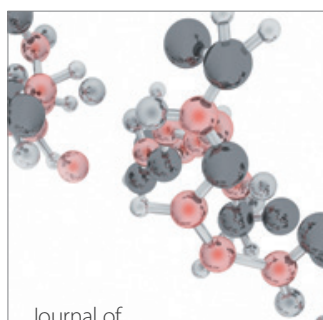

Analytical Methods

in Chemistry

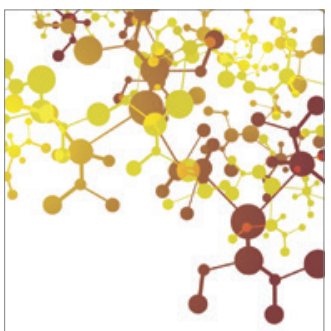

Journal of

Applied Chemistry

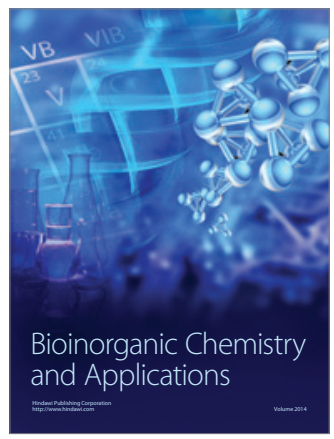

Inorganic Chemistry
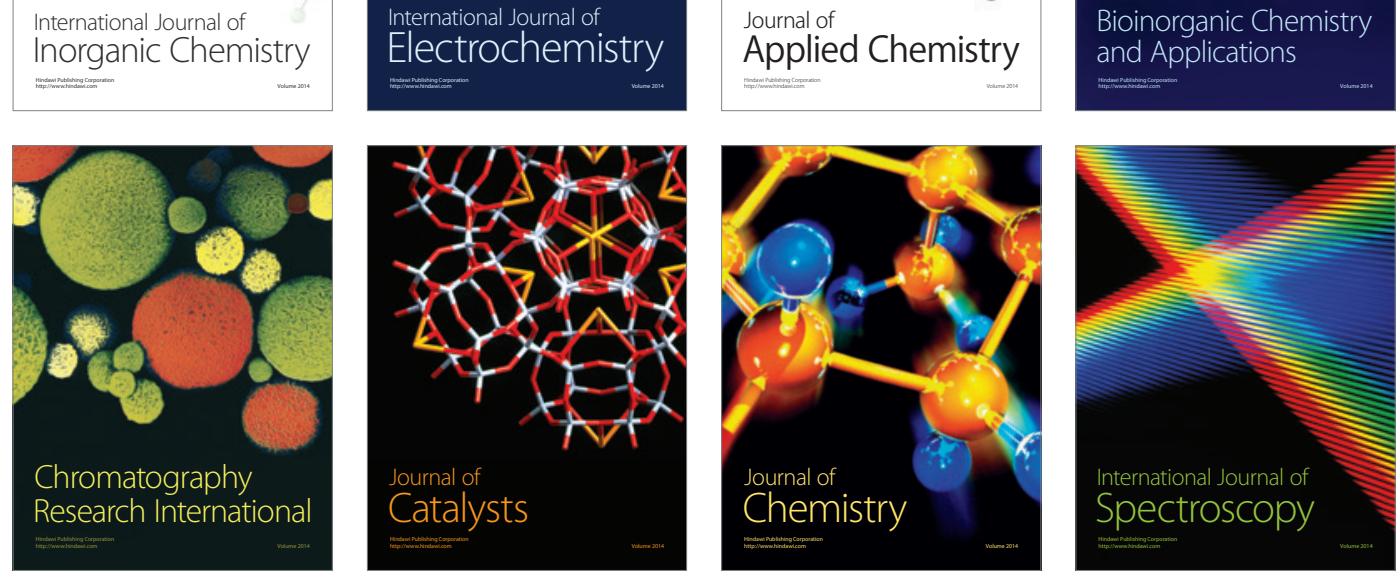